\title{
Rheological Properties of Polyamide PA 2200 in SLS Technology
}

\author{
Tomasz KOZIOR
}

\begin{abstract}
Mechanical properties, accuracy and tribological properties of additively manufactured models depend on the technological parameters. In the presented work, models made in selective laser sintering technology with modified technological parameters were analyzed.Therefore, the presented research attempts to determine the influence of two technological parameters (layer thickness in the $0.1-0.4 \mathrm{~mm}$ range and the printing direction $\left(0^{\circ}\right.$ and $\left.90^{\circ}\right)$ ) on stress relaxation determined during the uniaxial compression test (testing machine-Inspekt $3 \mathrm{kN}$ ) and on the mass of models (density of model material) manufactured by SLS technology with PA 2200 polyamide powder. Using the Origin software and the five-parameter rheological model of the so-called "Maxwell-Wiechert model", the rheological models of the samples were approximated, which allowed for the assessment of the possibility of adapting this rheological model for further investigations of additively produced models using SLS technology. The test results showed a clear effect of the layer thickness, both on the stress relaxation and on the mass of the produced models. In addition, it has been shown that the printing direction affects stress relaxation, however, it has no direct effect on the mass (density of the material) of the models. The variant $P D=0^{\circ}$ is the most favourable for enabling the production of models with the highest strength, and for the production of reduced weight models.
\end{abstract}

Keywords: additive manufacturing; polyamide PA 2200; rheology; selective laser sintering

\section{INTRODUCTION}

Prototype production using conventional or unconventional manufacturing technologies in many cases requires obtaining a product with properties corresponding to the models that are finally produced. Prototype elements are very often subjected not only to visual (organoleptic) assessment, as is the case, for example architectural mockups, but they must undergo many tests corresponding to the work of real (mass) manufactured components. In many cases, these elements are made of metal alloys or plastics reinforced with, for example, an addition in the form of fibreglass. Additionally, modern prototype production should be characterized by high flexibility. Currently, thanks to the use of software supporting design work after conducting a series of actual tests and additional simulations, there is almost immediate possibility of introducing changes in the prototype 3D model which, thanks to the use of additive technologies, allows immediate implementation of the new version of the prototype and testing.

The development of computer control systems supporting design work (CAD), simulation (CAE) and related to the manufacturing process (CAM) has resulted in a very intensive development of unconventional manufacturing technologies. This phenomenon is particularly evident in the case of additive manufacturing technologies [1], also known as rapid prototyping, layered technologies, and generative technologies. Additive manufacturing technologies have been known since the early 1980s when one of the first additive technologies was invented (stereolithography) [2]. This coincided with the dynamic development of CAD software, which at the beginning of the 1980s made it possible to create threedimensional objects and the appropriate digital STL file, approximating the model by means of triangles. Then, several additive technologies producing models layer by layer were patented, which differed both in the process of joining layers and the materials used, among others: SLM, FDM, SLS, LOM, 3DP. At the same time, the huge development in the field of material chemistry causes that additive technologies use materials based on plastics, metals and ceramics. Therefore, currently these technologies are used in many branches of industry such as foundries (SLA, SLS, PJM) [3, 4], injection molding (SLS, SLM), jewellery (SLS, SLA), food industry (SLS), medicine (SLA, SLS, SLM) [5], automotive and aviation industry (SLS, SLM, DMLS, LENS) [6]. Thanks to the enormous development of medicine, digital technology and chemistry, additive technologies allow to create models such as prostheses in the medical industry perfectly geometrically adapted to the shape of the patient. The socalled reverse engineering and computer tomography (CT) or magnetic resonance (RM) imaging is then used. Currently, thanks to the large bio-compatibility models produced by additive technologies are suitable for building models that have direct contact with food, which is confirmed by international standards, e.g. in SLS technology, this is ISO [7]. In addition, work is also being carried out to improve the so-called "printing" on already existing objects, for example in the textile industry [8]. The method of joining layers and the possibilities of using specific materials vary depending on the selected technology. The layered specificity of model construction and, in many cases, insufficiently reflective surface mean that large measurement problems arise, consisting in determining the mechanical properties of the produced models as well as the dimensional and shape accuracy and the surface texture quality. On the basis of the current state of knowledge on additive technologies, it can be stated that currently work is underway to develop standards for the standardization of measurement processes, which will undoubtedly improve the measurement procedures in the future.

In the case of manufacturing products, or their prototypes, which will work under constant load, rheological tests are often wrongly omitted. Stress relaxation and creep tests allow for real evaluation of material behaviour during constant loads. Undoubtedly, all kinds of connections ensuring tightness during real working conditions are subjected to constant loads which may result in a decrease of stresses ensuring tightness of the connection or even deformation of its elements [9]. In this case, it is important to consider rheological research at 
the stage of introducing changes and creating the prototype, the result of which may determine the final construction or material selection. The state of the literature on the research of rheological and mechanical properties as well as the dimensional and shape accuracy of models produced with additive SLS technology includes many publications, however, in most of the work the laser parameters are analyzed omitting the thickness of the layer being built and printing direction (PD).

In paper [10], the authors tested the samples made by selective laser sintering using PA 2200 polyamide powder. The main parameter analyzed was the influence of laser parameters on the tensile strength of the sample models. In addition, the influence of the printing direction was also examined. Unfortunately, within this research, there is no analysis of the thickness of the layer being built on the mechanical properties and a wide spectrum of the print direction (two variants were considered: $0^{\circ}$ and $90^{\circ}$ ).

Research on polyamide blends, in which two types of polyamides were used to build samples, was presented in paper [11]. During the tests, the authors made several types of mixtures of two well-known construction materials, polyamides: PA 6 and PA 12. The study also analyzed the impact of technological parameters such as: laser power, energy density and temperature of the building chamber. This paper also omits the influence of the thickness of the layer being built.

Measurements of dimensional accuracy of samples made with additive technology are also presented in paper [12], where the authors subjected the models, which were geometrically similar to typical foundry models, with particular emphasis on casting draft. The work also includes the influence of the print direction on the dimensional accuracy of the models. However, the research does not take into account the thickness of the layer being built and other technological parameters.

The influence of technological parameters on selected rheological properties, in particular stress relaxation of samples made in FDM technology is presented in article [13]. Using the rheological 5-parameter rheological model, relaxation modules were determined taking into account the influence of the printing direction. The material of the sample models was ABS P430 provided by the machine manufacturer (Dimension 1200es)-Stratasys. Moreover, the authors determined the compressive strength of the models, the most favorable variant of placing the samples on the platform during printing, and then proposed a rheological model with experimentally determined modules. As with other research this work also omits the analysis of the impact of the layer thickness on the mentioned properties.

An analysis of the geometric structure of the surface of samples made in Fused Deposition modeling technology is presented in [14]. The authors made a second type of sample, which was manufactured by conventional machining (turning), and then an in-depth analysis of the quality of the geometric surface texture was conducted with special consideration of $2 \mathrm{D}$ and $3 \mathrm{D}$ roughness parameters. The results of the tests showed that the structure obtained with FDM technology is characterized by different contact parameters and a significantly higher roughness in the aspect of SGP parameters.
The analysis of the impact of technological parameters of SLM laser additive technology on the quality of the geometric structure of the surface is described in [15]. The authors, using the InfiniteFocus optical microscope, tested the surfaces without frontal and lateral specimens made of Ti-6Al-4V material. The analyzed parameters were: laser power, scanning speed and energy density transmitted to the sintered powder layer. The test results showed that the basic parameters such as $S_{\mathrm{a}}$ and $S_{\mathrm{q}}$ do not depend in a linear way on the laser parameters. In addition, it has been shown that the lateral surfaces are characterized by better (smaller) values of roughness parameters in relation to the faces on which the laser beam directly fell.

To describe mechanical properties of manufactured models, several mathematical models can be used. In the case of simple stress states such as uniaxial tensile test or compression, one-parameter models of ideal bodies may be used to describe phenomena, e.g. Hooke's ideally elastic model (spring), Newton's model (dashpot) describing damping properties of materials or a perfectly plastic body model (slider) illustrating plastic permanent deformation of the material. In the case of more complex stress states, the models of Kelvin-Voigt, Maxwell, Prandtl, Standard III or Burgers and Bingham can be used to describe rheological phenomena. These models allow very precise description of stress relaxation or creep behaviour phenomena. The last group of models are multi-parameter models built using the prony series [16]. The works presented below describe the rheological measurements of models manufactured using additive technologies, in particular plastic materials (SLS, FDM, PJM).

Subsequent results of research on rheological properties of models produced with additive technologies are described in [17]. Models of samples were made using the Stratasys Connex 350 machine. Digital materials were used for the construction, enabling the production of new materials from individual material mixtures (TangoBlack and VeroWhite). Due to the fact that this technology enables the production of models with properties similar to those of rubber, the samples were designed in the form corresponding to the currently used static technical seals. The results of the research showed that the stress relaxation of sample for selected material groups with a very good approximation can be approximated by a 3-parameter rheological model-standard 1.

Due to the fact that SLS technology uses a number of materials additionally reinforced with, for example, glass fibre or aluminium powders, the research presented in this publication, which analyzes the influence of the layer thickness and the printing direction on stress relaxation and the mass of produced models, can be used for the other group of materials and seems reasonable. It seems particularly important to find a consensus between rheological properties and the mass of the produced models, which allows building models with satisfactory rheological properties and reduced mass, so important in the automotive and aerospace industry.

\section{MATERIALS AND METHODS}

In the presented research, a well-known Formiga P100 machine (EOS company) implementing selective laser sintering technology-SLS was used to build sample 
models. This machine allows the production of physical models from materials based on plastics with dimensions not exceeding the dimensions of the working chamber $250 \times 200 \times 330 \mathrm{~mm}^{3}$. Thanks to the use of a $\mathrm{CO}_{2}$ laser with a maximum power of $25 \mathrm{~W}$ and input material in the form of powder it is possible to manufacture objects without the need to build hard-to-remove support structures. No need to create supports, favourably affects the technological capabilities of manufacturing, as well as the technological quality of the surface layer. In addition, the powder nature of the process allows the creation of new materials with almost unlimited chemical composition, including those reinforced with additives such as glass fibre or aluminium. The production scheme using SLS technology is shown in Fig. 1. In the case of the presented tests, PA 2200 (see Tab. 1 , powder was based on the well-known construction polyamide PA 12, which is available in many configurations (fibreglass or aluminium addition) and can be cast. Not without significance is the fact that the models manufactured with this type of material are characterized by excellent thermal and tribological resistance, as described in several research papers e.g. [18]. The wear resistance of models manufactured by conventional and unconventional manufacturing technologies depends on many parameters which were described in paper [25]. The polyamide structure is shown in Fig. 1, where the distinguishing feature of polyamides against other polymers is amide bonds. $\mathrm{R}$ and $\mathrm{R}$ 'are alkyl group chains [19].<smiles>[R]C(=O)O</smiles><smiles>[R7]NC([R])=O</smiles>

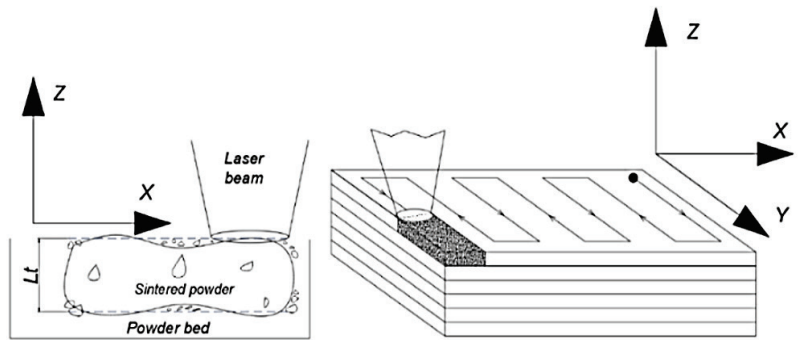

Figure 1 The principle of building models with SLS technology

Table 1 Polyamide PA 2200 characterization [20]

\begin{tabular}{|c|c|c|c|}
\hline Parameter & Symbol & Value & Notes \\
\hline Density & $\rho$ & $840 \mathrm{~kg} / \mathrm{m}^{3}$ & 1 bar, $270^{\circ} \mathrm{C}$, melt \\
\hline Surface tension & $\gamma$ & $25 \mathrm{mN} / \mathrm{m}$ & $265^{\circ} \mathrm{C}$, melt \\
\hline Melttemperature & $T_{\mathrm{m}}$ & $187{ }^{\circ} \mathrm{C}$ & $\begin{array}{c}\text { Equilibriummelting } \\
\text { point }\end{array}$ \\
\hline Specificheatcapacity & $c_{\mathrm{p}}$ & $\begin{array}{c}2.6 \\
\mathrm{~kJ} /(\mathrm{kg} \cdot \mathrm{K})\end{array}$ & $170{ }^{\circ} \mathrm{C}$ \\
\hline Thermalconductivity & $\kappa$ & $\begin{array}{c}0.24 \\
\mathrm{~W} /(\mathrm{m} \cdot \mathrm{K})\end{array}$ & $170{ }^{\circ} \mathrm{C}$ \\
\hline Surface reflectivity & $\zeta_{\mathrm{R}}$ & 0.05 & bulk, $1=200 \mu \mathrm{m}$ \\
\hline Transmittance & $\zeta_{\mathrm{T}}$ & 0.20 & bulk, $1=200 \mu \mathrm{m}$ \\
\hline $\begin{array}{c}\text { Convection } \\
\text { coefficient }\end{array}$ & $h$ & $\begin{array}{c}2.4 \\
\mathrm{~W} /\left(\mathrm{m}^{2} \cdot \mathrm{K}\right)\end{array}$ & powder surface \\
\hline Surface emissivity & $\varepsilon$ & 0.95 & powder surface \\
\hline Particle radius & $R$ & $30 \mu \mathrm{m}$ & PA 2200 \\
\hline $\begin{array}{c}\text { Absorption } \\
\text { coefficient }\end{array}$ & $\alpha$ & $7.9 \mathrm{~mm}-1$ & PA 2200 \\
\hline
\end{tabular}

Stress relaxation tests were carried out using the Hegewald \& Peschke Inspekt $3 \mathrm{kN}$ testing machine. The RADWAG AS $110 / \mathrm{C} / 2$ scale with a minimum measurement capacity of $10 \mathrm{mg}$ and a maximum of $110 \mathrm{~g}$ and a measurement accuracy of $0.0001 \mathrm{~g}$ was used to measure the mass of the models. Samples for testing were designed in Solidworks in accordance with ISO 3384 [21] standard for determining stress relaxation during the uniaxial compression test. The shape of the samples corresponds to a roller with a diameter of $13 \mathrm{~mm}$ and a height of $6.3 \mathrm{~mm}$. Then, the samples were manufactured using a 3D printer, which was characterized by the technological parameters presented in Tab. 2. Printed samples were subjected to the cleaning process using airpressure-washer. STL files of samples were saved with the following approximation parameters: linear tolerance 0.001 and angular tolerance of $10^{\circ} .8$ types of samples were designed, which were produced with different technological parameters. The research included the layer thickness $\left(L_{\mathrm{t}}\right)$, set on four degrees of variation, in the range of $0.1-0.4 \mathrm{~mm}$ and the printing direction $\left(P D-0^{\circ}\right.$ and $90^{\circ}$ ), as shown in Tab. 2 and Fig. 3 An attempt was made to make samples with a $L_{\mathrm{t}}$ of $0.5 \mathrm{~mm}$, however, these models were characterized by so low mechanical properties that it was impossible to carry out both their cleaning process and further tests (see Fig. 2). In total, 8 types of samples were created, each variant was made in 5 pieces to account for statistical calculations. The energy density transmitted to the sintered layer was calculated using Eq. (1) [24].

$$
E_{\mathrm{d}}=\frac{P}{v \cdot h} \cdot x=\frac{P}{v \cdot h} \cdot \frac{d}{h}=\frac{P \cdot d}{v \cdot h^{2}}
$$

where: $E_{\mathrm{d}}$ - energy density $\left(\mathrm{J} / \mathrm{mm}^{2}\right), P$ - laser power $(21 \mathrm{~W})$, $v$ - laser speed $(2500 \mathrm{~mm} / \mathrm{s}), h$ - hatch distance $(0.25 \mathrm{~mm})$, $d$ - laser beam diameter $(0.42 \mathrm{~mm}), x$ - beam overlay ratio (1.68).

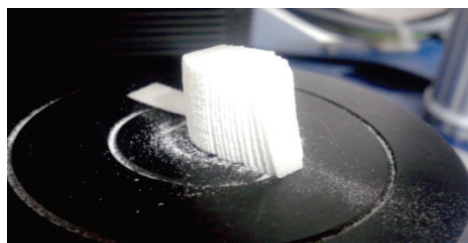

Figure 2 Samples destroyed during cleaning stage-layer thickness $0.5 \mathrm{~mm}$

a)

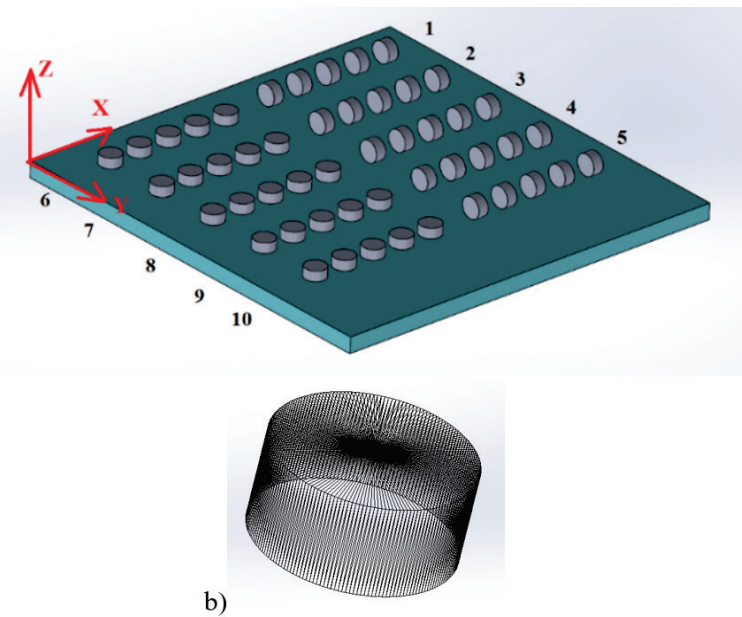

Figure 3 Samples: a) on the virtual platform, b) STL model 


\begin{tabular}{|c|c|c|c|}
\hline No. & $P D / 0$ & & \\
\hline 1 & \multirow{4}{*}{0} & & \multirow{8}{*}{0.056} \\
\hline & & & \\
\hline 3 & & 0.3 & \\
\hline 4 & & 0.4 & \\
\hline 5 & \multirow{4}{*}{90} & 0.1 & \\
\hline 6 & & 0.2 & \\
\hline 7 & & 0.3 & \\
\hline 8 & & 0.4 & \\
\hline
\end{tabular}

Rheological properties of materials subjected to continuous loading are determined experimentally, based on selected (known) one and two parameter rheological models [16, 22] (see Fig. 4 and Fig. 5).

a)

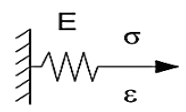

b)

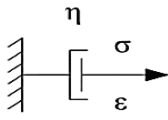

c)

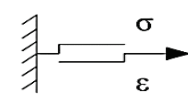

d)

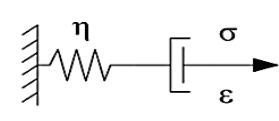

igure 4 Basic material models: a) Hooke'a, b) dashpots, c) friction sliders, d) Maxwell, e) Kelvin-Voigt
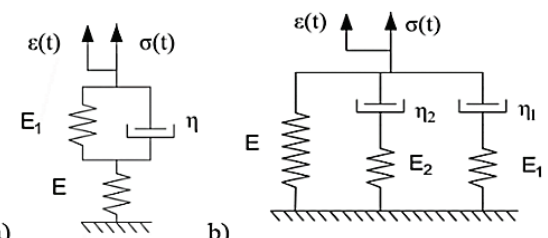

b)

Figure 5 Complex rheological models: a) Three-parameters model, b) Fiveparameters model

In the case of the presented studies, a more complex model (5 elements) consisting of two models of materials connected in parallel: Maxwell and Hooke, which are presented in Fig. 4b, was used to describe stress relaxation. Such combined models form a generalized Maxwell model also called the Maxwell-Weichert or Weichert model. In conditions of constant deformation and initial stress $\sigma_{1}$, stress after time t, $\sigma(t)$ can be determined by using Eq. 2 :

$\sigma(t)=\sigma_{1} \cdot H(t)$

where: $H(t)$ is a Heaviside function.

Differential equations of particular elements of the adopted rheological model can be presented by means of Eq. (3) (Hooke'a), Eq. (4) (Dashpots), Eq. (5) and Eq. (6) (Maxwell).

$$
\begin{aligned}
& \sigma=E \varepsilon \\
& \sigma=\eta \dot{\varepsilon} \\
& \sigma+\frac{\eta}{E} \dot{\sigma}=\eta \dot{\varepsilon}, \dot{\varepsilon}=\frac{\dot{\sigma}}{E}+\frac{\sigma}{\eta} \\
& \sigma(t)=\sigma_{0} \mathrm{e}^{\frac{-E}{\eta} t} ; \sigma(t)=E \varepsilon_{0} \mathrm{e}^{\frac{-E}{\eta} t}
\end{aligned}
$$

In the case of the stress relaxation model used, consisting of three elements, the constitutive equation takes the following Eq. (7), where the total generalized stress of the model is equal to the sum of stresses in its individual nodes.

$$
\sigma=\sum_{i=1}^{n} \sigma_{i}=\sum_{i=1}^{n} \frac{D_{\mathrm{t}}}{\frac{D_{\mathrm{t}}}{E_{i}}+\frac{1}{\eta_{i}}}
$$

where: $E$ - modulus of elasticity, $\varepsilon$ - strain, $\eta$ - dynamic viscosity, $t$ - time, $D_{\mathrm{t}}$ - differential operator.

In the Origin program, using the implemented Levenberg-Marquardt algorithm, mathematical models were determined in the form of approximating functions of the form presented below Eq. (8).

$$
y=y_{0}+A_{1} \mathrm{e}^{-x / t_{1}}+A_{2} \mathrm{e}^{-x / t_{2}}
$$

where: $y$-stress function, $y_{0}, A_{1}, A_{2}, t_{1}, t_{2}$-parameters of rheological models.

Fig. 8 and Fig. 9 show examples of approximation with a five-parameter relaxation Eq. (8) of experimental results. Tab. 5 presents the parameters of approximation functions with the determined test match indicators of $C h i^{2}$ and $R^{2}$. In addition, by analyzing the decrease in the stress value as a function of time using the Eq. (9) in ISO 3384, stress relaxation was determined for all variants of the orientation of the models on the building platform and four values of the layer thickness.

$$
\sigma(t)=\frac{\sigma_{0}-\sigma_{t}}{\sigma_{0}}
$$

where: $\sigma_{0}$ - initial compressive stresses, $\mathrm{N} / \mathrm{m}^{2}, \sigma_{\mathrm{t}}-$ compressive stresses after time $t, \mathrm{~N} / \mathrm{m}^{2}$.

\section{RESEARCH RESULT AND DISCUSSION 3.1 Stress Relaxation}

The results of stress relaxation tests are presented in

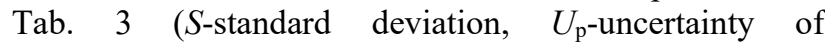
measurement.) and in Fig. 6 and Fig. 7, where the measurement results for four layer thicknesses were compared. In Tab. 4 , the symbol $\Delta \sigma_{0-200}$ indicates the decrease in stress as a function of time after the first 200 seconds of the test. This is the section with the most dynamic stress decrease. The $x$ symbol indicates the average relaxation value for all sample types. For samples made with $P D=0^{\circ}$, the stress curves as a function of time are also presented in Fig. 6 and for samples made at an angle of $90^{\circ}$ in Fig. 7.

Based on the results of stress relaxation tests, it can be stated that the layer thickness significantly influences the mechanical properties of the produced models. In addition, there are clear differences in the case of samples manufactured with different variants of model orientation on the platform-PD. 
Table 3 Statistical analysis of test results

\begin{tabular}{|c|c|c|c|c|c|c|c|}
\hline No. & $P D /{ }^{\circ}$ & $L_{\mathrm{t}}$ & $\bar{x}$ & $S$ & $U_{\mathrm{p}}$ & \multicolumn{2}{|c|}{$\bar{x} \pm U_{\mathrm{p}}$} \\
\hline 1 & \multirow{4}{*}{0} & 0.1 & 0.059 & 0.0002 & 0.019 & 0.040 & 0.078 \\
\hline 2 & & 0.2 & 0.173 & 0.0001 & 0.014 & 0.158 & 0.187 \\
\hline 3 & & 0.3 & 0.460 & 0.0015 & 0.049 & 0.411 & 0.509 \\
\hline 4 & & 0.4 & 0.502 & 0.0055 & 0.092 & 0.410 & 0.595 \\
\hline 5 & \multirow{4}{*}{90} & 0.1 & 0.063 & 0.002 & 0.002 & 0.061 & 0.065 \\
\hline 6 & & 0.2 & 0.266 & 0.006 & 0.007 & 0.258 & 0.273 \\
\hline 7 & & 0.3 & 0.346 & 0.014 & 0.017 & 0.329 & 0.363 \\
\hline 8 & & 0.4 & 0.349 & 0.005 & 0.006 & 0.343 & 0.355 \\
\hline
\end{tabular}

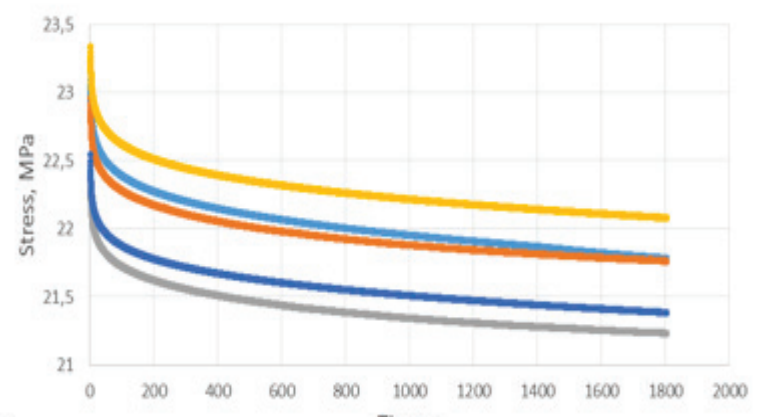

a)

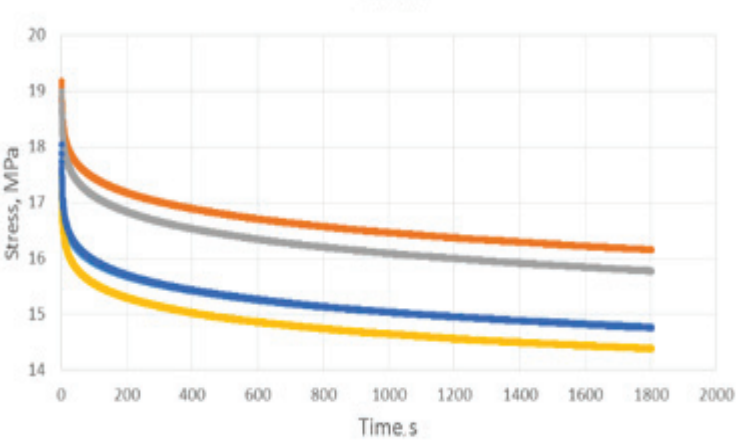

b)

c)
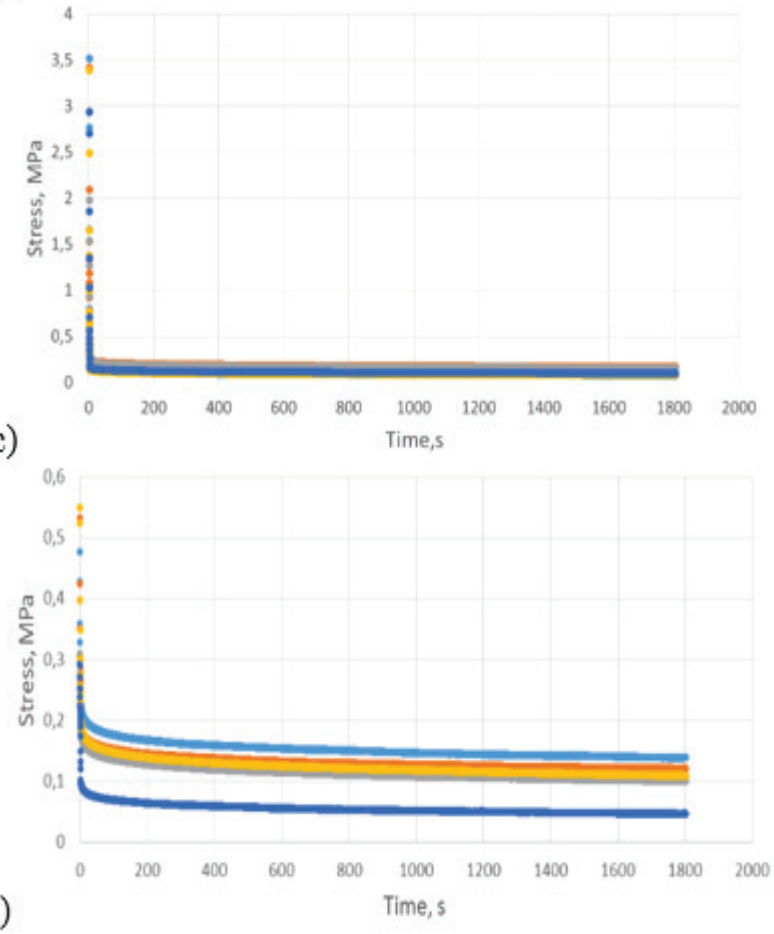

Figure 6 Stress relaxation $\left(P D=0^{\circ}\right)$ : a) $L_{\mathrm{t}}=0.1 \mathrm{~mm}$, b) $\left.L_{\mathrm{t}}=0.2 \mathrm{~mm}, \mathrm{c}\right) L_{\mathrm{t}}=$ $0.3 \mathrm{~mm}, \mathrm{~d}) L_{\mathrm{t}}=0.4 \mathrm{~mm}$
Table 4 Change in stress after the first 200 seconds

\begin{tabular}{|c|c|c|c|}
\hline No. & $P D /{ }^{\circ}$ & $L_{\mathrm{t}}$ & $\overline{\Delta \sigma}_{0-200} / \%$ \\
\hline 1 & \multirow{4}{*}{0} & 0.1 & 3.512 \\
\hline 2 & & 0.2 & 12.071 \\
\hline 3 & & 0.3 & 95.377 \\
\hline 4 & & 0.4 & 67.625 \\
\hline 5 & \multirow{4}{*}{90} & 0.1 & 4.071 \\
\hline 6 & & 0.2 & 7.361 \\
\hline 7 & & 0.3 & 27.871 \\
\hline 8 & & 0.4 & 27.861 \\
\hline
\end{tabular}

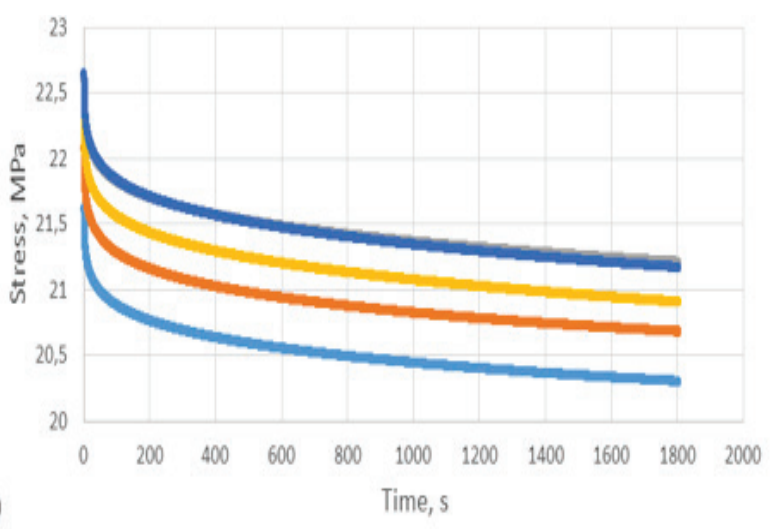

a)

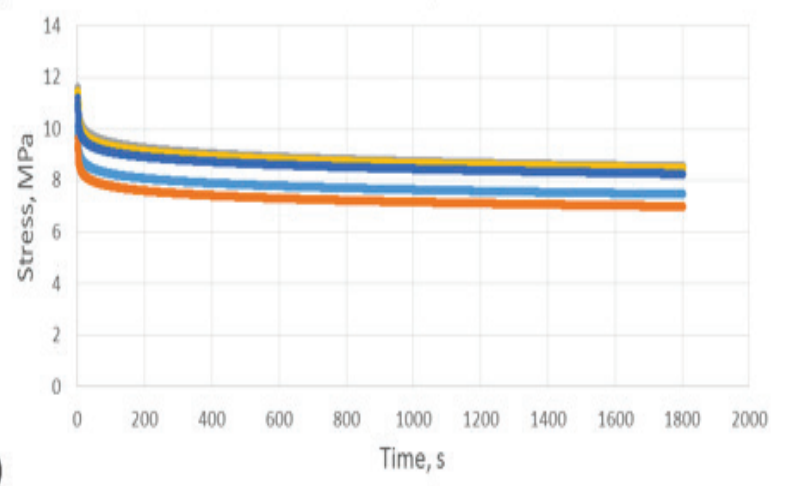

b)
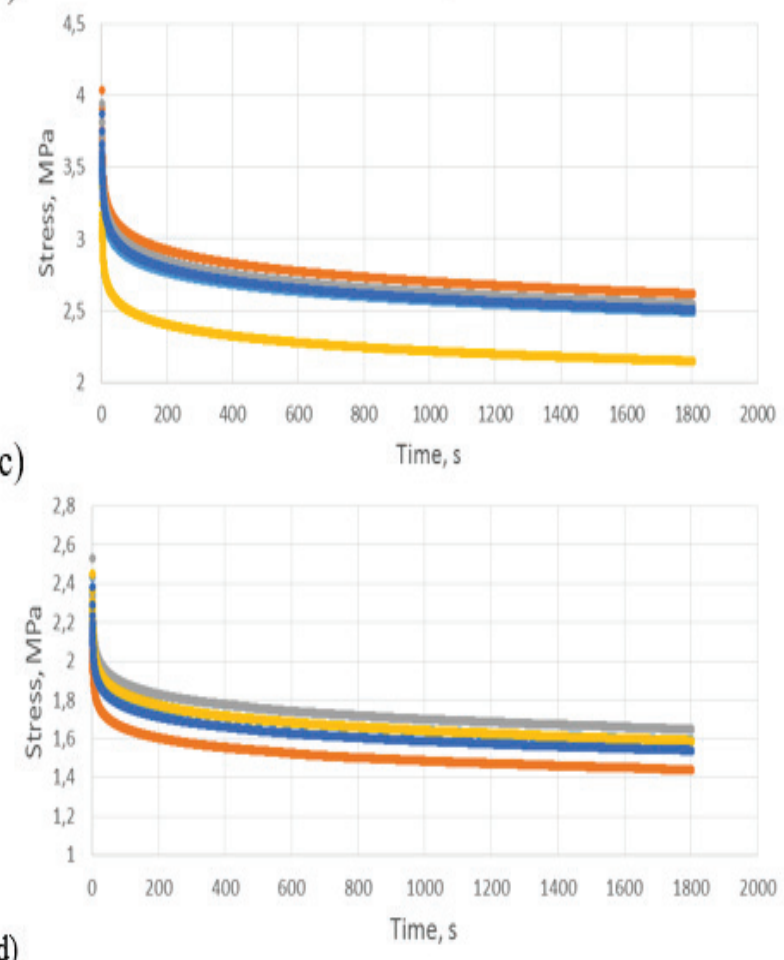

Figure 7 Stress relaxation $\left(P D=90^{\circ}\right)$ : a) $\left.\left.L_{\mathrm{t}}=0.1 \mathrm{~mm}, \mathrm{~b}\right) L_{\mathrm{t}}=0.2 \mathrm{~mm}, \mathrm{c}\right) L_{\mathrm{t}}=$ $0.3 \mathrm{~mm}, \mathrm{~d}) L_{\mathrm{t}}=0.4 \mathrm{~mm}$ 
a)
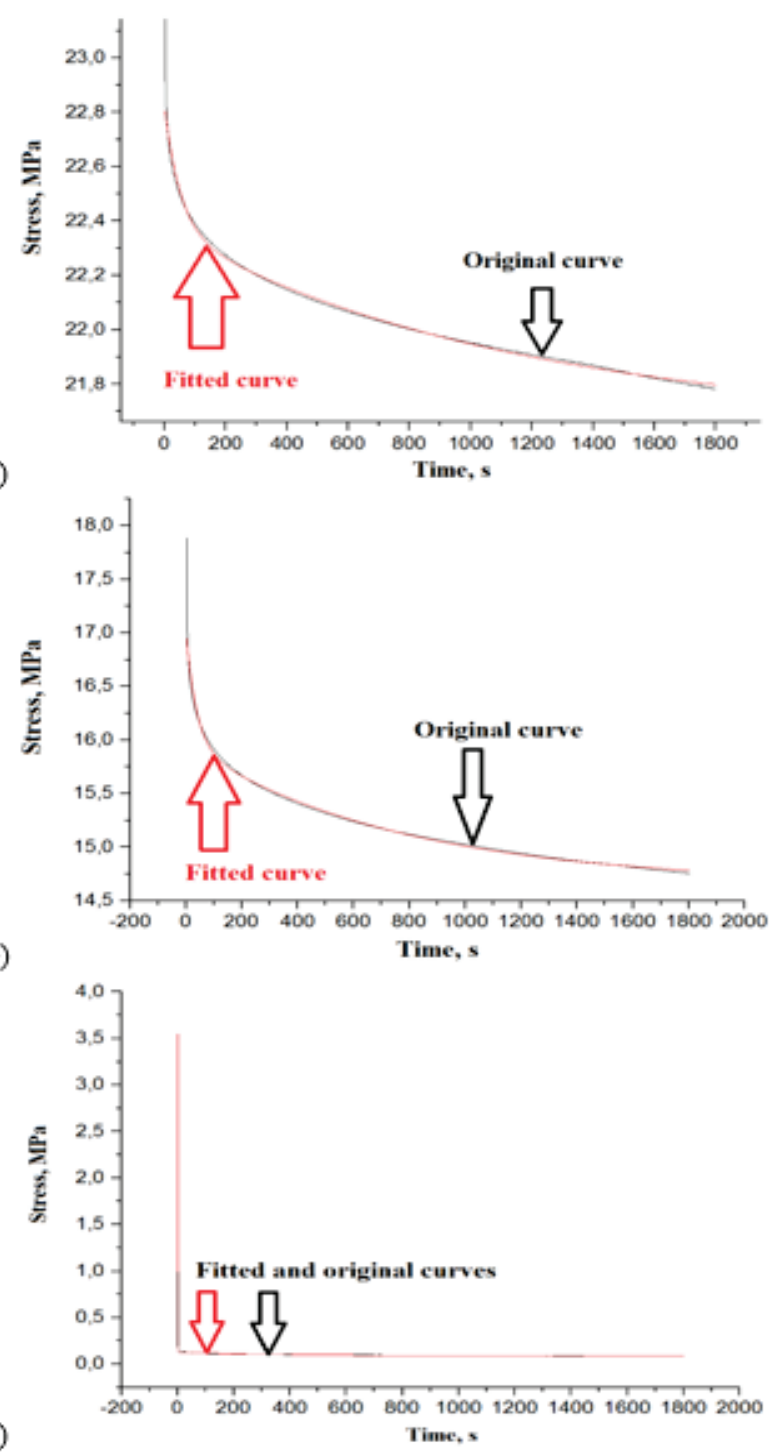

c)

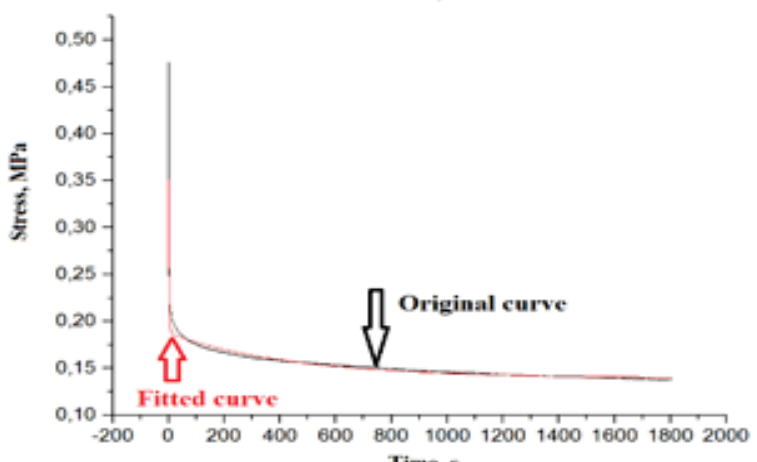

d)

Figure 8 Approximation with a 5 parameter function, $P D=0^{\circ}$ : a) $L_{\mathrm{t}}=0.1$, b) $L_{\mathrm{L}}$ $=0.2$, c) $L_{\mathrm{t}}=0.3$, d) $L_{\mathrm{t}}=0.4$

Table 5 Results for approximation functions

\begin{tabular}{|c|c|c|c|c|c|c|c|}
\hline No & $y_{0}$ & $A_{1}$ & $A_{2}$ & $t_{1}$ & $t_{2}$ & $C h i^{2}$ & $R^{2}$ \\
\hline 1 & 21.655 & 0.454 & 0.716 & 52.111 & 1118.1 & 0.00012 & 0.996 \\
\hline 2 & 14.663 & 1.055 & 1.295 & 37.793 & 758.59 & 0.00056 & 0.996 \\
\hline 3 & 0.088 & 0.039 & 104.3 & 397.63 & 0.304 & 0.00001 & 0.993 \\
\hline 4 & 0.139 & 0.214 & 0.047 & 2.110 & 443.54 & 0.000008 & 0.957 \\
\hline 5 & 20.230 & 0.451 & 0.657 & 45.292 & 852.057 & 0.00009 & 0.997 \\
\hline 6 & 7.416 & 0.949 & 0.877 & 30.502 & 669.005 & 0.00045 & 0.993 \\
\hline 7 & 2.476 & 0.466 & 0.397 & 28.494 & 653.660 & 0.000111 & 0.992 \\
\hline 8 & 1.578 & 0.282 & 0.251 & 30.214 & 674.245 & 0.000043 & 0.993 \\
\hline
\end{tabular}

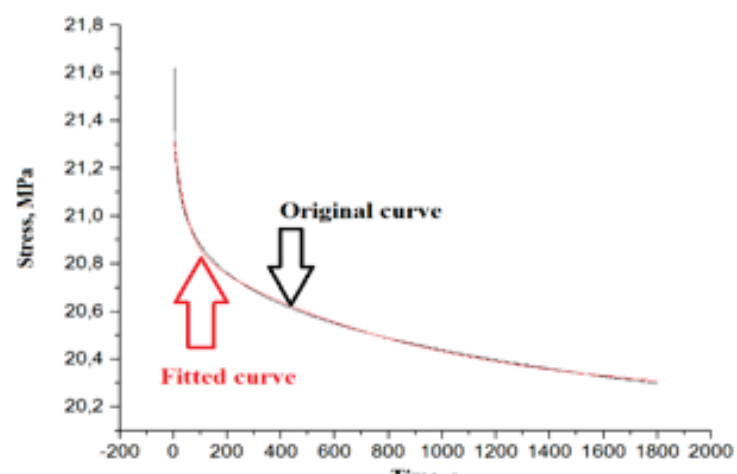

a)

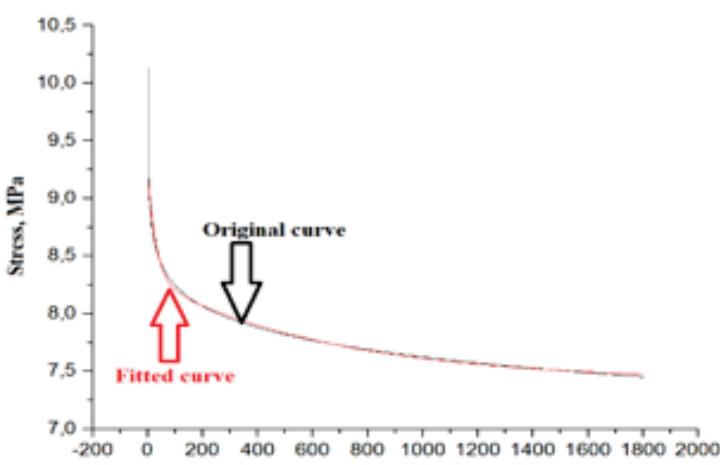

b)

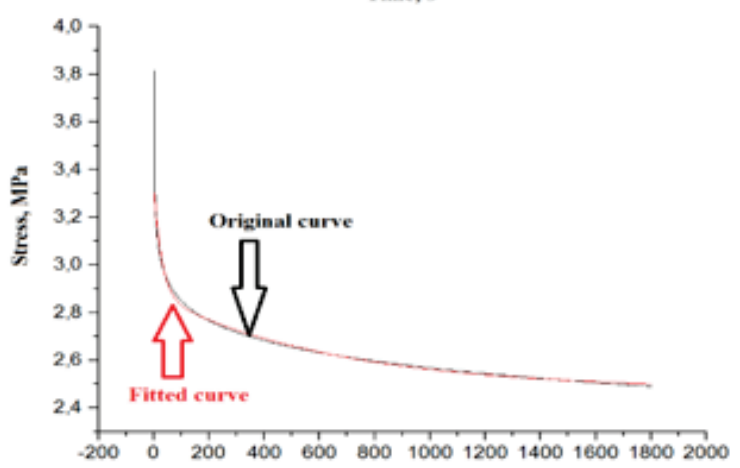

c)

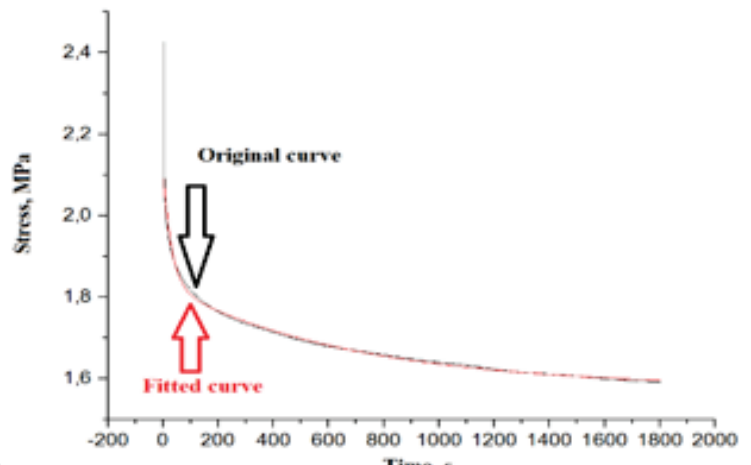

d) Time, s

Figure 9 Approximation with a 5 parameter function, $P D=90^{\circ}$ : a) $L_{\mathrm{t}}=0.1$, b) $L_{\mathrm{t}}=0.2$, c) $L_{\mathrm{t}}=0.3$, d) $L_{\mathrm{t}}=0.4$

Taking into account the value of the force which was measured at the beginning of the relaxation test, one can notice clear differences in the results. Samples $1-4$ manufactured in the $P D=0^{\circ}$ variant were characterized by the initial force value of $1-1796 \mathrm{~N}, 2-1439 \mathrm{~N}, 3-254 \mathrm{~N}$ and $4-33 \mathrm{~N}$ respectively. On the other hand, samples 5 8 , made with a given $P D=90^{\circ}$, were characterized by an initial force of $1-1747$ N, $2-843$ N, $3-298$ N and 4 - 188 $\mathrm{N}$.

In the first two cases $(L T=0.1$ and $L T=0.2)$ higher values of the initial force were recorded for the first 
orientation paradigm of $P D=0^{\circ}$ models. In the case of variants where $L T$ is 0.3 and $0.4 \mathrm{~mm}$, the value of the initial force in the orientation of the model on the platform at an angle of $P D=90^{\circ}$ was higher.

Comparing the results, it can be concluded that in the case of the layer thickness of the $0.1 \mathrm{~mm}$, there is no clear difference in the compressive strength of the sample models, however, with the increase of $L_{\mathrm{t}}$ the strength decreases unevenly. It is clearly visible that samples made with a given layer thickness of $0.2 \mathrm{~mm}$ and $P D=0^{\circ}$ are characterized by over $50 \%$ greater strength compared to the same type of samples and the $P D=90^{\circ}$. The same characteristic is found for samples manufactured with layer thickness of the $0.3 \mathrm{~mm}$, however the difference is much less visible.

The test results in relation to the value of the layer thickness recommended by the machine manufacturer, which is $0.1 \mathrm{~mm}$, clearly indicate an increase in the value of stress relaxation as a function of the increase of the layer thickness. In the case of the first variant of orientation the models on the building platform $\left(P D=0^{\circ}\right)$, increasing the value of the layer thickness by $0.1 \mathrm{~mm}$ to the level of 0.2 $\mathrm{mm}$ causes an increase in stress relaxation by over $193 \%$. Another $L_{\mathrm{t}}$ increase to $0.3 \mathrm{~mm}$ and $0.4 \mathrm{~mm}$ intensifies this phenomenon, and the value of relaxation increases by more than $600 \%$ and $700 \%$, respectively.

In the case of the second variant of model distribution on the building platform $\left(P D=90^{\circ}\right)$, the relaxation of model samples made with the set layer thickness at the level of $0.2 \mathrm{~mm}$ causes an increase in stress relaxation by over $300 \%$. It is almost twice as much as in the variant discussed above $\left(P D=0^{\circ}\right)$. Subsequent increased layers to the level of $0.3 \mathrm{~mm}$ and $0.4 \mathrm{~mm}$, respectively, also cause an increase in stress relaxation, by over $300 \%$.

In the case of samples manufactured with given recommended technological parameters, a more favorable (smaller) value of stress relaxation was obtained for the $P D$ $=0^{\circ}$ variant $(R(t)=0.059)$ in relation to $P D=90^{\circ}$, where $R(t)=0.063$. In addition, it can be noticed that with the increase in the layer thickness, the value of initial stresses decreases, which means lower mechanical properties.

Analyzing samples manufactured with a given layer thickness of $0.5 \mathrm{~mm}$, it can be stated that while maintaining standard technological parameters and increased layer thickness to the level of $0.5 \mathrm{~mm}$, it is impossible to properly connect layers, but only to sinter the given layer.

The function with the 5-parameter Maxwell-Wiechert model allows for precise approximation of the stress-time curve, which is evidenced by the value of $R^{2}$ close to 1 (almost in all cases above 0.99). Only the curve for samples with layer thickness of $0.4 \mathrm{~mm}$, parameter $R^{2}$ assumes values slightly lower than one, amounting to 0.957 .

\subsection{Mass}

The mass measurement of sample models was carried out before stress relaxation tests and after the cleaning process. The samples marked with $1-4$ numbers were characterized by a layer thickness of 0.1 to $0.4 \mathrm{~mm}$ and $P D$ $=0^{\circ}$. Samples marked with numbers $5-8$ were prepared with the same thickness values of the layer being built and the $P D=90^{\circ}$. The results of the tests in the form of diagrams are presented in Fig. 10. Tab. 6 presents the results of mass measurements of samples $x_{\mathrm{m}}$ and calculated material density $x_{D}$. Tab. 7 shows statistical calculations of test results for the 0.05 confidence level.

Table 6 The results of mass measurement of the tested samples

\begin{tabular}{|c|c|c|c|c|}
\hline No & $P D$ & $L_{\mathrm{t}}$ & Mass / $\bar{x}_{\mathrm{m}}$ & Density / $\bar{x}_{\mathrm{D}}$ \\
\hline 1 & \multirow{4}{*}{0} & 0.1 & 0.748 & 0.959 \\
\hline 2 & & 0.2 & 0.602 & 0.772 \\
\hline 3 & & 0.3 & 0.516 & 0.662 \\
\hline 4 & & 0.4 & 0.466 & 0.597 \\
\hline 5 & \multirow{4}{*}{90} & 0.1 & 0.752 & 0.964 \\
\hline 6 & & 0.2 & 0.592 & 0.759 \\
\hline 7 & & 0.3 & 0.510 & 0.654 \\
\hline 8 & & 0.4 & 0.432 & 0.554 \\
\hline
\end{tabular}

Table 7 Statistical analysis of test results - material density

\begin{tabular}{|c|c|c|c|c|c|c|}
\hline No & $P D$ & $\bar{x}$ & $S$ & $U_{\mathrm{p}}$ & \multicolumn{2}{|c|}{$\bar{x} \pm U_{\mathrm{p}}$} \\
\hline 1 & \multirow{4}{*}{0} & 0.959 & 0.006 & 0.007 & 0.952 & 0.966 \\
\hline 2 & & 0.772 & 0.014 & 0.017 & 0.754 & 0.789 \\
\hline 3 & & 0.662 & 0.007 & 0.009 & 0.653 & 0.670 \\
\hline 4 & & 0.597 & 0.015 & 0.018 & 0.579 & 0.616 \\
\hline 5 & \multirow{4}{*}{90} & 0.964 & 0.006 & 0.007 & 0.957 & 0.971 \\
\hline 6 & & 0.759 & 0.006 & 0.007 & 0.752 & 0.766 \\
\hline 7 & & 0.654 & 0.009 & 0.011 & 0.643 & 0.665 \\
\hline 8 & & 0.554 & 0.011 & 0.013 & 0.541 & 0.567 \\
\hline
\end{tabular}

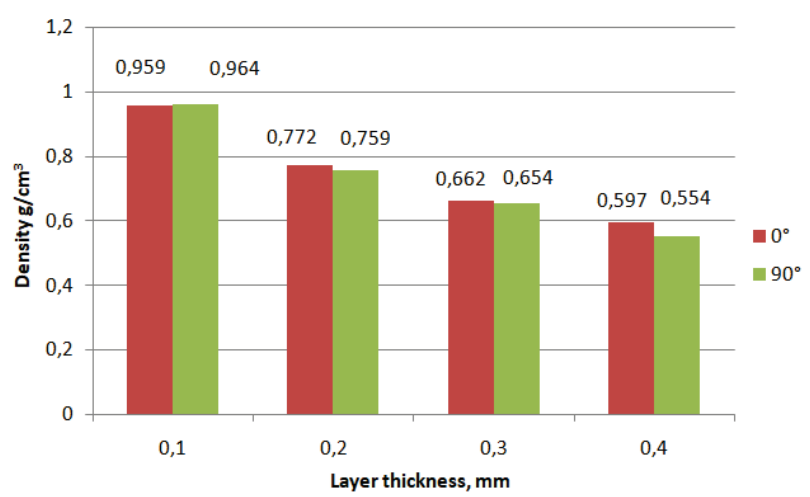

Figure 10 Material density

Quantitative analysis of the mass measurement results of the produced samples showed that with the increase in the layer thickness, the mass of the models (density of the material) decreases, regardless of the $P D$. In all cases of model orientation relative to the building platform, the weight loss of the sample models is almost linear. Samples manufactured with the standard technological parameters recommended by the machine manufacturer were characterized by a density of $0.959 \mathrm{~g} / \mathrm{cm}^{3}$ and $0.964 \mathrm{~g} / \mathrm{cm}^{3}$ $\left(0^{\circ}\right.$ and $90^{\circ}$, samples number 1 and 5$)$. Increasing the layer thickness by $0.1 \mathrm{~mm}$ reduces the density of the model material regardless of the printing direction by more than $20 \%$ (samples number 2 and 6). In case of layer thickness increased to the level of $0.3 \mathrm{~mm}$ and $0.4 \mathrm{~mm}$, there was a significant decrease in the mass of models reaching more than $30 \%$ (samples number 3, 4, and 7, 8). In addition, samples made with extreme parameters enabling relaxation tests (samples 4 and 8) were characterized by the density of the model material at the level of $0.55-0.6 \mathrm{~g} / \mathrm{cm}^{3}$. This density is similar to the density of the model material in the powdered state, i.e. the material in the input state.

Taking into account the whole research results, it should be stated that by using selective laser sintering (SLS) technologies, it is possible to build models with reduced mass (up to 30\%) while maintaining satisfactory strength properties $(R(t))$. Samples made with a given layer 
thickness of $0.2 \mathrm{~mm}$ weighed over $20 \%$ less than the samples made with a given thickness of $0.1 \mathrm{~mm}$, however, the strength and rheological properties remained at a satisfactory level. Organoleptic assessment of the samples allows concluding that the models made with increased thickness of the layer showed less deformation, typical for SLS technology, arising during the cooling process. The less weight of the model means less material that needs to be cooled, which positively affects the level of generated thermal stresses and the cooling process and quality [23]. It is worth mentioning that in many cases, in particular when prototype elements are manufactured, it is important that the construction time is as low as possible and the high-dimensional size and shape accuracy. Reducing the energy density by increasing the laser speed and maintaining the same power and increasing the thickness of the layer being built has a positive effect both on the building time and on the mass of the created detail lowering it. It also allows to obtain elements with greater dimensional and shape stability, which is associated with lower temperature gradients during the cooling process after completion of the building process and increases the cooling rate of the models.

\section{CONCLUSIONS}

Based on the research results on the impact of the layer thickness and the printing direction on the stress relaxation and the mass of the models, the following general conclusions can be formulated:

1. Layer thickness is a key parameter affecting stresses relaxation, mechanical strength of built models and density of model material. With increasing the layer thickness, stress relaxation increases, and the density of the model material and compressive strength decreases. The function of the decrease of the initial value of the compressive force for the variable thickness of the layer is not consistent. For $L_{\mathrm{t}}=0.1$ and 0.2 we can observe a sharp decrease, above this value $\left(L_{\mathrm{t}}=0.3\right.$ and 0.4$)$ it is moderate.

2. The approximation of the stress relaxation function using the 5-parameter Maxwell-Wiechert model allows for a very precise reproduction of the stress decrease as a function of time for the models produced by SLS additive technology and polyamide powder PA 2200.

3. The highest layer thickness, which enables the cleaning process to be carried out and further tests, is 0.4 $\mathrm{mm}$. Above this value delamination is clearly visible, which prevents further processes. In addition, it was determined that the direction of printing does not affect the mass of the models, regardless of the layer thickness. The curve displaying the density change as a function of the layer thickness is almost linear.

4. The layer thickness and the printing direction affect the strength of the models being built, which was observed based on the analysis of the initial value of the compressive force. The orientation variant $P D=0^{\circ}$ is the most advantageous variant enabling the construction of models with the highest strength, and in the case of increasing the layer thickness $L_{\mathrm{t}}$ on the production of reduced weight models.

This allows for the conclusion that correctly selected layer thickness, laser power and printing orientation can reduce the mass of models while maintaining satisfactory mechanical properties.

\section{REFERENCES}

[1] ASTM F2792-12a, Standard Terminology for Additive Manufacturing Technologies, (Withdrawn 2015), ASTM International, West Conshohocken, PA, 2012, www.astm.org

[2] Hull, C. (1986). Apparatus for production of threedimensional objects by stereolithography. US $4575330 \mathrm{~A}$.

[3] Adamczak, S., Zmarzły, P., Kozior, T., \& Gogolewski, D. (2017). Analysis of the dimensional accuracy of casting models manufactured by fused deposition modeling technology. Engineering Mechanics, 66-69.

[4] Coniglio, N., Sivarupan, T., \& Mansori, M. El. (2018). Investigation of process parameter effect on anisotropic properties of 3D printed sand molds. Journal of Advanced Manufacturing Technology, 94, 2175-2185. https://doi.org/10.1007/s00170-017-0861-5

[5] Dzhendov, D. \& Dikova, T. (2016). Application of selective laser melting in manufacturing of fixed dental prostheses. Journal of IMAB, 22, 1414-1417. https://doi.org/10.5272/jimab.2016224.1414

[6] Rokicki, P., Budzik, G., Kubiak, K., Bernaczek, J., Dziubek, T., Magniszewski, M., Nowotnik, A., Sieniawski, J., Matysiak, H., Cygan, R., \& Trojan, A. (2014). Rapid prototyping in manufacturing of core models of aircraft engine blades. Aircraft Engineering and Aerospace Technology, 86, 323-327. https://doi.org/10.1108/AEAT-10-2012-0192

[7] ISO 10993-1:2010, Biological evaluation of medical devices - Part 1: Evaluation and testing within a risk management process.

[8] Kozior, T., Döpke, C., Grimmelsmann, N., Junger I. J., \& Ehrmann, A. (2018). Influence of fabric pretreatment on adhesion of three-dimensional printed material on textile substrates. Advances in Mechanical Engineering, 10(8), 1-8. https://doi.org/10.1177/1687814018792316

[9] Kundera, Cz. \& Kozior, T. (2014). Research of the Elastic Properties of Bellows Made in SLS Technology. Advanced Materials Research, 874, 77-81. https://doi.org/10.4028/www.scientific.net/AMR.874.77

[10] Pilipović, A., Brajlih, T., \& Drstvenšek, I. (2018). Influence of Processing Parameters on Tensile Properties of SLS Polymer Product. Polymers, 10, 1-18. https://doi.org/10.3390/polym10111208

[11] Salmoria, G. V., Leite, J. L., Veira, L. F., Pires, A. T. N., \& Roesler, C. R. M. (2012). Mechanical properties of PA6/PA12 blend specimens prepared by selective laser sintering. Polymer Testing, 31, 411-416. https://doi.org/10.1016/.j.polymertesting.2011.12.006

[12] Adamczak, S., Zmarzły, P., Kozior, T., \& Gogolewski, D. (2017). Assessment of roundness and waviness deviations of elements produced by selective laser sintering technology. Engineering Mechanics, 70-73.

[13] Kundera, Cz. \& Kozior, T. (2017). Evaluation of the influence of parameters of FDM technology on the selected mechanical properties of models. Procedia Engineering, 192, 463-468. https://doi.org/10.1016/j.proeng.2017.06.080

[14] Krolczyk, G., Raos, P., \& Legutko, S. (2014). Experimental analysis of Surface roughness and Surface texture of machined and Fused Deposition modeling parts. Tehnički vjesnik, 21(1), 217-221.

[15] Józwik. J., Ostrowski, D., Milczarczyk, R., \& Krolczyk, G. (2018). Analysis of relation between the 3D printer laser beam power and the surface morphology properties in Ti6Al-4V titanium alloy parts. Journal of the Brazilian Society of Mechanical Sciences and Engineering, 40(215), 1-10. 
https://doi.org/10.1007/s40430-018-1144-2

[16] Bochnia, J. (2018). Evaluation of relaxation properties of digital materials obtained by means of PolyJet Matrix technology. Bulletin of the Polish Academy of Sciences, 66, 891-897.

[17] Kundera, Cz., Martsynkowskyy, V., Gudkov, S., \& Kozior, T. (2017). Effect of rheological parameters of elastomeric ring materials on dynamic of face seals. Procedia Engineering, 177, 307-313. https://doi.org/10.1016/j.proeng.2017.02.230

[18] Sebestyén, T., Takács, J., Tóth, L., Franek, F., \& Pauschitz, A. (2001). Tribological Aspects of Wear of Laser-Sintered Rapid Prototype Tools. Fundamentals of Tribology and Bridging the Gap Between the Macro- and Micro/Nanoscales, 10, 571-576. https://doi.org/10.1007/978-94-010-0736-8_44

[19] Verbelen, L., Dadbakhsh, S., Van den Eynde, M., Kruth, J. P., Goderis, B., \& Van Puyvelde, P. (2016). Characterization of polyamide powders for determination of laser sintering processability. European Polymer Journal, 75, 163-174. https://doi.org/10.1016/j.eurpolymj.2015.12.014

[20] Balemansa, C., Jaenssona, N. O., Hulsena, M. A., \& Anderson, P. D. (2018). Temperature-dependent sintering of two viscous particles. Additive Manufacturing, 24, 528-542. https://doi.org/10.1016/j.addma.2018.09.005

[21] ISO 3384-1:2011 Rubber, vulcanized or thermoplastic Determination of stress relaxation in compression -- Part 1: Testing at constant temperature.

[22] Bochnia, J. \& Blasiak, S. (2018). Fractional relaxation model of materials obtained with selective laser sintering technology. Rapid Prototyping Journal, 1-11. https://doi.org/10.1108/RPJ-11-2017-0236

[23] Stępień, K., Makieła, W., Stoic, A., \& Samardzic, I. (2015). Defining the criteria to select the wavelet type for the assessment of surface quality. Tehnički vjesnik, 22(3), 781784. https://doi.org/10.17559/TV-20140124110406

[24] Pilipović, A., Valentan, B., Brajlih, T., Haramina, T., Balič, J., Kodvanj, J., Šercer, M., \& Drstvensek, I. (2012). Influence of laser sintering parameters on mechanical properties of polymer products. The $3^{\text {rd }}$ International Conference on Additive Technologies; DAAAM Specialized Conference, 2010, Nova Gorica, Slovenia.

[25] Bartkowiak, T., Berglund, J., \& Brown, C. A. (2018). Establishing functional correlations between multiscale areal curvatures and coefficients of friction for machined surfaces. Surface Topography-Metrology and properties, 6, 1-9. https://doi.org/10.1088/2051-672X/aac073

\section{Contact information:}

Tomasz KOZIOR, PhD,

(Corresponding author)

Kielce University of Technology,

Al. 1000-lecia P. P. 7, 25-314 Kielce, Poland

E-mail: tkozior@tu.kielce.pl 